\title{
PERSONALITY CHARACTERISTICS \\ AND CONFLICT PREDISPOSITIONS IN TEAMS MARITZA \\ AND RAKOVSKI FROM BULGARIAN WOMEN'S \\ NATIONAL VOLLEYBALL LEAGUE
}

Ivan Ivanov, Vladimir Kotev

National Sports Academy "Vassil Levski", Sofia, Bulgaria

\begin{abstract}
Introduction: In the game of volleyball, game efficiency is based not only on physical preparation and technical skills. A great deal of it depends on the players'abilities to cooperate, communicate and adapt to the psychosocial aspects of team group dynamics. In this study we attempt to establish the players' behavior in conflict situations, their basic personality characteristics and how these influence some game indicators.

Methodology: 1) Background information; 2) Thomas-Kilmann Conflict Mode Instrument (1977); 3) Big Five Personality Test developed by Goldberg (1992).

Results: The results of our research reveal that the scale with the highest result is Compromising, which is the trait described by both assertiveness and cooperativeness. We have significant differences between teams and age groups in terms of the scale Competing from the Thomas-Kilmann Conflict Mode Instrument and Conscientiousness and Agreeableness from the Big Five Personality Test.

Conclusions: The younger players are more open and try to find more information about the sports environment and learn more about the game and their personal growth. The higher the qualification and the age, the more the players prefer competing and being assertive in their interpersonal relationships. The lower level players prefer clearer rules and instructions. The players from Maritza are more sport aggressive and with a higher winners'attitude.
\end{abstract}

Key words: interpersonal relationship, women volleyball players, personality traits

\section{INTRODUCTION}

The structure of our personality is based on some different parameters and traits, which are described as dispositions to reaction in one or another way. Since 1980 researchers have begun to agree on the basic personality structures. Many authors have determined five independent dimensions through surveys with selfreport questionnaires across different cultures and countries (McCrae \& John, 1992). All five factors show high convergent and discriminatory validity with other instruments and with observers' reports and have been stable for de- cades (Pervin, L. A., \& John, O. P. 1997; McCrae, \& John, 1992).

The two basic models of conceptualization of the modern five-factor model of personality are attributed to Goldberg and Costa \& McCrae (Goldberg, 1990, 1992; Costa \& McCrae, 1992a, 1992b, 2008). Goldberg's model is known as the "Big five", and Costa \& McCrae's model - as the "Five factors". The first structure is described by factors like Extraversion, Agreeableness, Conscientiousness, Emotional stability and Intellect (Goldberg, 1990, 1992). The second - by factors like 
Neuroticism, Extraversion, Openness to experience, Conscientiousness and Agreeableness (Costa \& McCrae, 1992a, 1992b, 2008). The original instrument was developed by Goldberg (2001) and was adapted for Bulgaria by Karamanova (2016).

The analysis of the internal consistency shows high reliability of the Bulgarian version of the instrument. Cronbach's alphas are as follows: Emotional stability $\alpha=0.810$; Extraversion $\alpha=0.794$; Agreeableness $\alpha=0.786$; Conscientiousness $\alpha=0.759$; Intellect $\alpha=0.709$. For the whole questionnaire $-\alpha=0.821$ (Karamanova, 2016).

The personality traits concept is closely related to the interpersonal relationship theory. There are two basic styles of interaction - cooperation and competing. The first dimension is described as agreeableness, sympathy and helpfulness. People with this style are productive during conflict situations and for them it is more typical to cooperate with others. The second characteristic is based on mistrust, hostility and destructive behavior.

According to Iancheva (2004) the complicated contemporary situation in elite sport is based on the very high expectations toward the personality of athletes, their behavior and sport performance. All these circumstances make the role of personal integrity an essential factor for the preparation and realization of competitive strategies.

Blake and Mouton (1964) published the original dual model for acting during conflicts, also described as the "conflict grid". These conflict styles are based on two separate dimensions, "concern for people" and "concern for production". Several similar models have since emerged - Hall (1969), Thomas and Kilmann (1974), Rahim (1983), Pruitt (1983), and Pruitt and Rubin (1986). The models include variation of "concern for self" and "concern for others" and depend on whether indi- viduals prefer one of these two dimensions.

Thomas and Kilmann (1974) described five styles of conflict resolution: competing (high concern for self, low concern for others); collaborating (high concern for both self and others); compromising (moderate concern for self and for others); accommodating (low concern for self and high for others); and avoiding (low concern for self and for others).

In sports psychology, the comparison between personality and sport success is a very appealing issue that can help to understand which personality dimensions are associated with greater levels of success. The association is very complex and therefore different motivational and dispositional variables correlate with sport performance. Success has been described in terms of the competition level and previous results on the Big Five have shown that high-level athletes (e.g., athletes competing at a national or international level) are more agreeable, conscientious, and with higher emotional stability.

The aim of the present research is to study and establish the personal traits and interpersonal relationships (the level of two dimensions assertiveness and cooperativeness) of two women volleyball teams (Maritza and Rakovski) and to compare the results in terms of age, practice, qualification.

\section{METHODOLOGY \\ Participants}

The research was done among 27 women volleyball players aged between 17 and 34 years with different level of practice and qualification. The mean age of researched individuals is 21.4. For the purpose of the research the players were divided into groups as follows: according to their experience: 6-10 years (17 players), 11-23 years (10 players); according to their age: 17-23 (20 players), 2434 (7 players); according to participation in 
"A" national team of their countries -8 out of 27 players.

\section{Methods}

In order to fulfill the aim of the research we used:

Background information. To obtain appropriate demographic data, we used a questionnaire to ascertain details such as age, sport and competitive experience.

Thomas-Kilmann Conflict Mode Instrument (1977). Thomas-Kilrnann instrument has 30 pairs of statements describing modes of handling conflict. Each mode is paired with the other four modes an equal number of times. Subjects are asked to choose the statement in each pair that best describes their behavior in a conflict situation. A profile of behavior for handling conflict is obtained by summing the number of statements the subject endorses for each mode. This instrument is specifically designed to minimize the effect of social-desirability response bias (Kilmann $\&$ Thomas, 1977). Based on the concept of Thomas and Kilmann we can describe an individual's behavior along two dimensions: (1) assertiveness, the extent to which the person attempts to satisfy his own concerns, and (2) cooperativeness, the extent to which the person attempts to satisfy the other person's concerns. These dimensions are described by five different scales: Competing, Accommodating, Avoiding, Collaborating, Compromising.

Big Five Personality Test. The big five personality traits are the best accepted and most commonly used model of personality in academic psychology. The big five come from the statistical study of responses to personality items. Using a technique called factor analysis researchers can look at the responses of people to hundreds of personality items and ask the question "what is the best way to summarize an individual?". This has been done with many samples from all over the world and the general result is that, while there seem to be unlimited personality variables, five stand out from the pack in terms of explaining a lot of people's answers to questions about their personality: extraversion, neuroticism, agreeableness, conscientiousness and openness to experience. The big five are not associated with any particular test, a variety of research methods have been developed to measure them. In this study we used the Bulgarian adaptation (Karamanova, 2016), based on the Big-Five Factor Markers from the International Personality Item Pool, developed by Goldberg (1992).

Statistical methods. To analyze the initial data from the research, we used the statistical program SPSS 23 and conducted variation, correlation and comparative analyses.

\section{RESULTS}

The results of the average values of all 27 competitors (Figure 1) showed that the scale with the highest result $(M=7.37)$ was Compromising, which is the trait described by both assertiveness and cooperativeness. The players displayed high level of agreement and conformity. The next characteristic was Collaborating $(M=6.81)$. Accommodation $(M=6.59)$ and Avoiding $(M=5.55)$ ranked third and fourth respectively. The scale with the lowest score was Competing $(M=4.22)$. We can see that the scales regarding cooperativeness, the extent to which the person attempts to satisfy the other person's concerns, had higher results. 


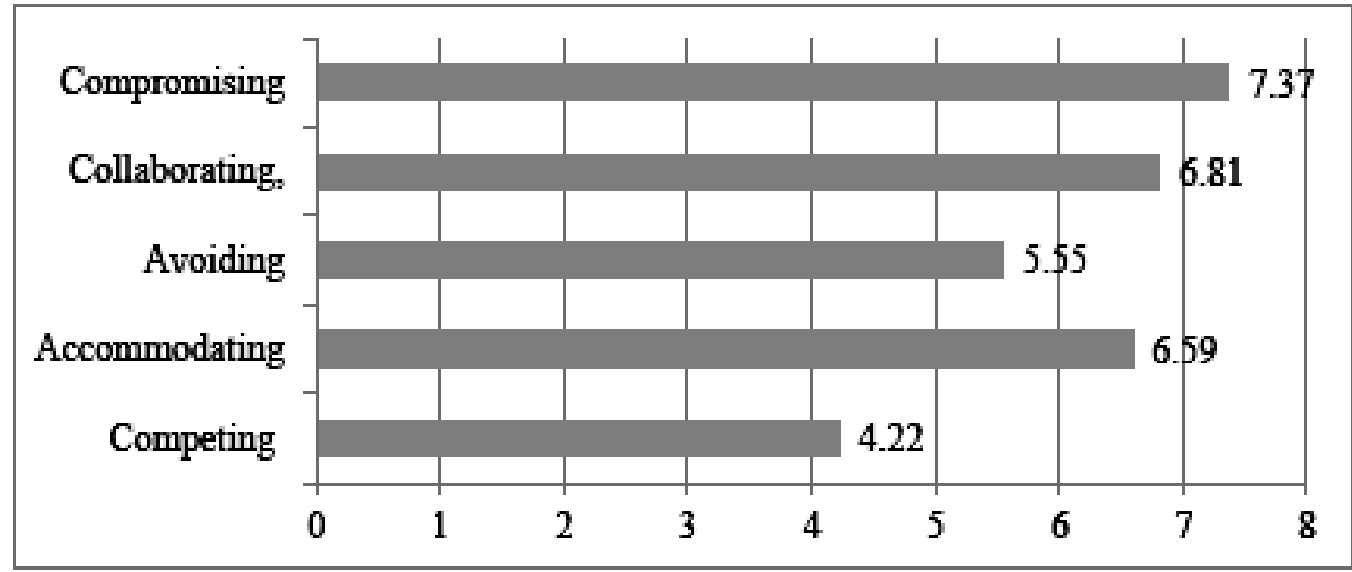

Figure 1. Mean values of compromising, collaborating, avoiding, accommodating and competing

All these results are expected and normal if we take into account the characteristics of volleyball and the basic personality traits which are important for the successful competitive career of the players. Like in most team sports, the results depend on the actions and behavior of all competitors and the data in our research showed that the scales with high results were Compromising, Collaborating and Accommodating. These three different styles define conflict solving as a basic priority value which comes before any personal interests and goals. This is the core structure when we build a functional team, and it is tremendously important for obtaining good results. On the other hand, we have the two scales from Thomas-Kilmann instrument-Avoiding, when the player tries to stay away from trouble, and Competing, when they try to win their own position.

The mean values from the Big Five Personality Test showed that the scales Conscientiousness and Agreeableness had the same high score $-M=41$. The two levels are described in Goldberg's theory and in different scientific reports as traits of people who tend to reflect more on the individuality of others and adjust their behavior in order to suit them. High scorers are typically polite and they like people. Low scorers tend to 'tell it like it is'. Conscientiousness is the personality trait of being honest and hardworking. High scorers tend to follow rules. Low scorers may not be well-organized and tend to cheat. Neuroticism was the lowest scale $(M=30.00)$, it means that most of the players exhibit medium emotional stability in comparison to the general population.

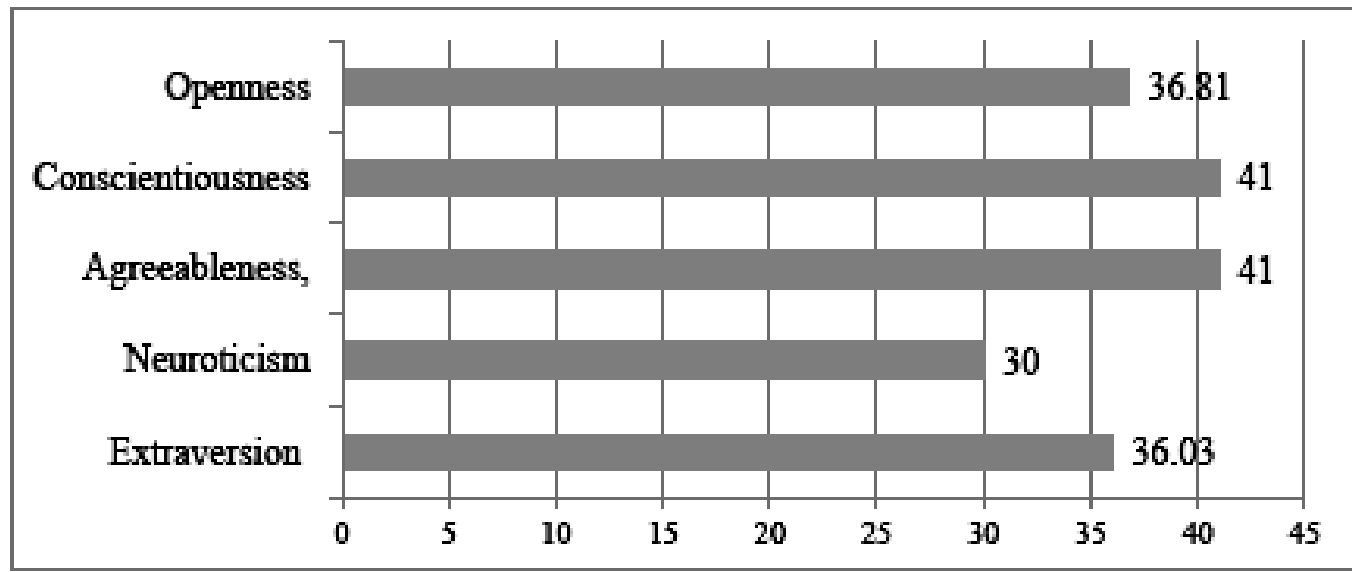

Figure 2. Mean values of openness, conscientiousness, agreeableness, neuroticism and extraversion. 
The next analysis is comparative by age for divided the respondents into two groups 17-23 all players in the research. For this purpose, we (20 players), 24-34 (7 players).

Table 1. Comparative analysis of the researched parameters by age

\begin{tabular}{|c|c|c|c|c|c|c|}
\hline Parameter & Age & $\mathbf{N}$ & $\mathbf{M}$ & SD & $\mathbf{t}$ & $\alpha$ \\
\hline \multirow{3}{*}{ Competing } & $17-23$ & 20 & 3.55 & 3.22 & & \\
\hline & $24-34$ & 7 & 6.14 & 2.74 & 3.64 & 0.05 \\
\hline & Total & 27 & 4.22 & & & \\
\hline \multirow{3}{*}{ Collaborating } & $17-23$ & 20 & 6.85 & 1.50 & & \\
\hline & $24-34$ & 7 & 6.71 & 0.93 & 0.233 & 0.81 \\
\hline & Total & 27 & 6.81 & & & \\
\hline \multirow{3}{*}{ Compromising } & $17-23$ & 20 & 7.55 & 1.61 & & \\
\hline & $24-34$ & 7 & 6.85 & 1.67 & 0.972 & 0.34 \\
\hline & Total & 27 & 7.37 & & & \\
\hline \multirow{3}{*}{ Avoiding } & $17-23$ & 20 & 5.65 & 1.30 & & \\
\hline & $24-34$ & 7 & 5.28 & 1.24 & 0.656 & 0.51 \\
\hline & Total & 27 & 5.55 & & & \\
\hline \multirow{3}{*}{ Accommodating } & $17-23$ & 20 & 6.75 & 2.06 & & \\
\hline & $24-34$ & 7 & 6.14 & 2.28 & 0.624 & 0.53 \\
\hline & Total & 27 & 6.59 & & & \\
\hline \multirow{3}{*}{ Extraversion } & $17-23$ & 20 & 35.00 & 5.58 & & \\
\hline & $24-34$ & 7 & 39.00 & 6.69 & -1.54 & 0.13 \\
\hline & Total & 27 & 36.03 & & & \\
\hline \multirow{3}{*}{ Agreeableness } & $17-23$ & 20 & 41.20 & 4.01 & & \\
\hline & $24-34$ & 7 & 40.57 & 6.67 & 0256 & 015 \\
\hline & Total & 27 & 41.03 & & 0.250 & \\
\hline \multirow{3}{*}{ Conscientiousness } & $17-23$ & 20 & 41.05 & 5.47 & & \\
\hline & $24-34$ & 7 & 40.85 & 5.31 & 0.79 & 0.93 \\
\hline & Total & 27 & 41.00 & & & \\
\hline \multirow{3}{*}{ Neuroticism } & $17-23$ & 20 & 29.65 & 6.64 & & \\
\hline & $24-34$ & 7 & 31.14 & 10.66 & -0.392 & 0.69 \\
\hline & Total & 27 & 30.03 & & & \\
\hline \multirow{3}{*}{ Openness } & $17-23$ & 20 & 36.25 & 4.56 & & \\
\hline & $24-34$ & 7 & 38.42 & 4.01 & 2.28 & 0.02 \\
\hline & Total & 27 & 36.81 & & & \\
\hline
\end{tabular}

The data (Table 1) show that there were and sport experience. significant differences in two of the scales Competing and Openness. The first parameter was higher in older athletes $(t=3.21$; $\alpha=0.01)$. They are more assertive, with more sport aggression and motivation to win. We can hypothesize that this is due to the social
The second scale with different results $(t=3.21 ; \alpha=0.01)$ was Openness. It refers to people who seek new experiences and intellectual pursuits, trying to learn something new in their daily life and profession. The younger players displayed higher results regarding this 
trait, they are more open and ready to develop.

The other purpose of our research was to compare the parameters between the two teams - Maritza and Rakovski. Table 2 shows a comparative analysis of all parameters in our research by team. The two teams are part of the Bulgarian volleyball league but take very different qualification places in the champi- onship. Maritza is the best in Bulgaria, with two participations in the Champions League for the last two seasons. Rakovski is one of the teams in our championship, whose best achievement is second place two years ago. The players from Maritza are more qualified, most of them are part of the national teams of their own countries.

Table 2. Comparative analysis of the researched parameters between the teams

\begin{tabular}{|c|c|c|c|c|c|c|}
\hline Parameter & Team & $\mathbf{N}$ & $\mathbf{M}$ & SD & $\mathbf{t}$ & $\alpha$ \\
\hline \multirow{3}{*}{ Competing } & Maritza & 15 & 5,60 & 3,22 & & \\
\hline & Rakovski & 12 & 2,50 & 2,74 & 2,64 & 0,01 \\
\hline & Total & 27 & 4,22 & & & \\
\hline \multirow{3}{*}{ Collaborating } & Maritza & 15 & 6,53 & 1,50 & & \\
\hline & Rakovski & 12 & 7,16 & 0,93 & -1.27 & 0,57 \\
\hline & Total & 27 & 6,81 & & & \\
\hline \multirow{3}{*}{ Compromising } & Maritza & 15 & 7,20 & 1,61 & & \\
\hline & Rakovski & 12 & 7,58 & 1,67 & $-0,60$ & 0,89 \\
\hline & Total & 27 & 7,37 & & & \\
\hline \multirow{3}{*}{ Avoiding } & Maritza & 15 & 5,53 & 1,30 & & \\
\hline & Rakovski & 12 & 5,58 & 1,24 & $-0,10$ & 0,76 \\
\hline & Total & 27 & 5,55 & & & \\
\hline \multirow{3}{*}{ Accommodating } & Maritza & 15 & 6,13 & 2,06 & & \\
\hline & Rakovski & 12 & 7,16 & 2,28 & $-1,23$ & 0,28 \\
\hline & Total & 27 & 6,59 & & & \\
\hline \multirow{3}{*}{ Extraversion } & Maritza & 15 & 36,73 & 5,58 & & \\
\hline & Rakovski & 12 & 35,16 & 6,69 & 0,66 & 0,54 \\
\hline & Total & 27 & 36,03 & & & \\
\hline \multirow{3}{*}{ Agreeableness } & Maritza & 15 & 39,60 & 4,01 & & \\
\hline & Rakovski & 12 & 42,83 & 6,67 & 2,56 & $\mathbf{0 , 0 3}$ \\
\hline & Total & 27 & 41,03 & & & \\
\hline \multirow{3}{*}{ Conscientiousness } & Maritza & 15 & 39,86 & 5,47 & & \\
\hline & Rakovski & 12 & 42,41 & 5,31 & 3,21 & $\mathbf{0 , 0 1}$ \\
\hline & Total & 27 & 41,00 & & & \\
\hline \multirow{3}{*}{ Neuroticism } & Maritza & 15 & 30,86 & 6,64 & & \\
\hline & Rakovski & 12 & 29,00 & 10,66 & 0,55 & 0,42 \\
\hline & Total & 27 & 30,03 & & & \\
\hline \multirow{3}{*}{ Openness } & Maritza & 15 & 36,60 & 4,56 & & \\
\hline & Rakovski & 12 & 37,08 & 4,01 & $-0,28$ & 0,27 \\
\hline & Total & 27 & 36,81 & & & \\
\hline
\end{tabular}

Table 2 shows there were significant differences $(t=2.64 ; \alpha=0.01)$ between the teams when it comes to the scale Competing. The results showed that the players from Maritza scored higher. The more experienced and qualified team and players demonstrate more skills and tend to put their own interests first. Most of them are players with very extensive experience and prefer to be assertive in most of the situations. The competitors of Maritza know their rights better, they are willing to make an effort to be part of the team and take their own 
place on the court. The players from the other team are not assertive enough and they may have confidence issues during the game. They have to be emotionally stable and to defend their position, to find their place in the team, if they want to achieve their goals.

The next scale with significant differences was Agreeableness $(t=2.56 ; \alpha=0.03)$. Rakovski's players displayed higher results. The characteristic is described as the way people tend to reflect more on the individuality of others and adjust their behavior in order to suit them. High scorers are typically polite and like people. Low scorers tend to 'tell it like it is'. We can observe again that the better qualified volleyball players showed more assertiveness when compared to Rakovski's. But on the other hand, more agreeableness means more "team players", which is important in volleyball. It is clear that a good team needs to have leaders and it is important to demonstrate sport aggressive behavior on many occasions during practice and games.

The third scale with significant differences was Conscientiousness $(t=3.21 ; \alpha=0.01)$. Rakovski scored better here. The typical description of this trait includes high level organizational skills and motivation with clear goals. People prefer to follow the rules and the moral code, but sometimes they are rigid and not flexible enough in their behavioral responses. We can say that for less experienced players it is very important to have a good and professional description of tactical tasks, because they need clearer directions. They do not prefer to improvise and to switch their behavior quickly in accordance with the situation. The more experienced players from Maritza adapt better in the core and basic characteristics of volleyball - rapidly changing situations.

As a whole, the results showed that the competitors from Maritza have higher asser- tiveness, are more ambitious and demonstrate a freer exchange of information and persuasion and a more active involvement.

The correlation analysis showed there were only two significant correlations between the researched parameters. The first correlation is negative - scale Competing with scale Agreeableness (- 0.433). We can consider that more assertiveness and competitiveness are traits which are not associated with conformism and agreeableness. The dimensions show that most of the players who prefer team cohesion behavior do not display enough sport aggression and are ready to take responsibility in complicated game situations.

The other significant correlation was between accommodating and openness (0.469). It is positive and we can conclude that the two dimensions often go together as part of the psychological profile of the players. People who are open to new experiences and challenges easily adapt to new situations, practices and competitions.

\section{DISCUSSION}

The results of the study lead to some interesting conclusions. As a whole, the results indicate that the mean value of Compromising has the highest score. Competing is the scale with the lowest points. The data show that these traits are important for volleyball as a team game and confirms that the attitudes to conflict and to deviant thinking and behavior are not typical in many of the situations. In the theory the research instrument is based on, the level of conflict disposition of the players is low. This is one of the core indicators for good group cohesion.

The second test "Big five" indicates that Conscientiousness and Agreeableness are the scales with the highest scores. This means that the results, where the researched competitors prefer to act with more conformity, corre- 
spond with the dimensions from the ThomasKilmann Conflict Mode Instrument.

The teams in the research are part of the Bulgarian championship, but their results and their qualifications are very different. The younger players are more open and try to find information about the sports environment and learn more about the game and their personal growth.

There are significant differences between the teams and the different age groups regarding the scale Competing. The higher the qualification and the age, the more the players prefer competing and being assertive in their interpersonal relationships. When we compare the teams in our survey, the more experienced Maritza displays a higher level of competitiveness, which means more sport aggression. And this style of behavior is very useful and important during games, it is part of the winners' attitude.

Team Rakovski has higher scores on the scales Agreeableness and Conscientiousness. There are significant differences between the teams, which means that lower level players prefer clearer rules and instructions. This style is useful for the players' development, but in sports like volleyball they have to think and react spontaneously in a lot of unpredictable situations. Usually this is the core difference between the more qualified competitors and the others.

\section{REFERENCES:}

Blake, R. R., \& Mouton, J. S. (1964). The managerial grid: The key to leadership excellence. Houston, TX: Gulf.

Costa, P. T., Jr., \& McCrae, R. R. (1992a). Normal personality assessment in clinical practice: The NEO Personality Inventory. Psychological Assessment, 4 (1), pp.5-13.

Costa, P. T., Jr., \& McCrae, R. R. (1992b). Revised NEO Personality Inventory (NEO
PIR $^{\mathrm{TM}}$ ) and NEO Five-Factor Inventory (NEO-FFI) professional manual. Odessa, FL: Psychological Assessment Resources.

Costa, P. T., Jr., \& McCrae, R. R. (2008). The Revised NEO Personality Inventory (NEOPI-R), in G.J.Boyle, G. Matthews \& D. H. Saklofske, The Sage Handbook of Personality Theory and Assessment, Vol. 2:Personality Measurement and Testing (pp. 179-198). London: SAGE Publications.

Goldberg, L. R. (1990). An alternative "description of personality": The Big-five factor structure. Journal of Personality and Social Psychology, 59 (6) pp.1216-1229.

Goldberg, L. R. (1992). The development of markers for the Big-five factor structure. Psychological Assessment, 4, pp.26-42.

Goldberg, L. R. (2001). International Personality Item Pool - IPIP. http://ipip.ori.org/

Hall, J. (1969) Conflict management survey: A survey on ones characteristic reaction to and handling of conflicts between himself and others. Conroe, TX: Teleometrics International.

Iancheva, T. (2004). Lichnost I sastezatelna realizaciq, S., NSA PRES. (In Bulgarian) Янчева, Т. (2004). Личност и състезателна реализаичия, С., НСА ПРЕС.

Karamanova, A., (2016). Rakovodstvo za izpolzwane na balgarskata versiq na lichnostniq vaprosnick "Pette golemi". Bulgarian Academy of Science, Department of psychology (In Bulgarian) Караманова, A., (2016). Ръководство за използване на българската версия на личностния въпросник „Петте големи“. Българска Академия на Науките, Департамент по психология.

McCrae, R. R. \& John, O. P. (1992). An Introduction to the Five-Factor Model and Its Applications. Journal of Personality, 60, pp.175-215.

Pervin, L. A., \& John, O. P. (1997). Personality theory and re- search (7th ed.). New 
York: Wiley.

Rahim, M. A. (1983). A measure of styles Pruitt, D. G. (1983). Strategic Choice in of handling interpersonal conflict. Academy of Negotiation. American Behavioral Scientist. Management Journal, 26(2), 368-376.

Pruitt, D. G., \& Rubin, J. Z. (1986). Social

Thomas, K. W., and Kilmann, R. H. (1974).

conflict: escalation, stalemate, and settlement. The Thomas-Kilmann Conflict Mode InstruNew York, Random House, Harvard (18th ed.). ment. Mountain View, CA: CPP, Inc.

\section{Corresponding author:}

\section{Ivan Ivanov}

Department "Psychology, Pedagogy, Sociology"

National Sports Academy "Vassil Levski" 21 Acad. Stefan Mladenov, str. Sofia, Bulgaria E-mail: ywan13@abv.bg 